\title{
Confirmation of linkage of hyperkalaemic periodic paralysis to chromosome 17
}

\author{
Manuela C Koch, Kenneth Ricker, Michael Otto, Tiemo Grimm, Eric P Hoffman, \\ Reinhardt Rüdel, Klaus Bender, Barbara Zoll, Peter S Harper, Frank Lehmann-Horn
}

\begin{abstract}
Linkage studies were performed in six European families with hyperkalaemic periodic paralysis (PPII) with myotonia, an autosomal dominantly inherited disorder characterised by episodic weakness. The weakness is caused by non-inactivating sodium channels of reduced single channel conductance of the muscle fibre membrane. Recently, portions of the gene coding for the $\alpha$ subunit of the sodium
\end{abstract}

Zentrum für Humangenetik, Abteilung Allgemeine Humangenetik der Philipps Universität Marburg, Bahnhofstrasse 7, 355 Marburg, Germany.

M C Koch, M Otto

Neurologische Universitätsklinik Würzburg, Josef Schneider Strasse 11, 87 Würzburg, Germany. K Ricker

Institut für Humangenetik, Universität Würzburg, Koellikerstrasse 2, 87 Würzburg, Germany.

T Grimm

Department of Molecular Genetics and Biochemistry, University of Pittsburg School of Medicine, Pittsburgh, PA 15261, USA.

E P Hoffman

Abteilung für Allgemeine Physiologie der Universität Ulm, Albert Einstein Allee 11, 79 Ulm, Germany.

R Rüdel

Institut für Humangenetik, Universität Freiburg, Breisacher Strasse 33, 78 Freiburg, Germany.

K Bender

Institut für Humangenetik, Universität Göttingen, Gosslerstrasse 12d, 34 Göttingen, Germany. B Zoll

Institute of Medical Genetics, University of Wales College of Medicine, Heath Park, Cardiff CF4 4XN. P S Harper

Neurologische Klinik der Technischen Universität München, Möhlstrasse 28, 8 München 80, Germany. F Lehmann-Horn

Correspondence to Dr Koch.

Received for publication 12 February 1991

Accepted for publication 3 April 1991. channel of the adult human skeletal muscle (h-Na2) have been cloned and localised on chromosome $17 q$ with no recombinants to the human growth hormone locus (GH1). Linkage between these two chromosome 17 markers and the disease was shown in our families $(Z=7 \cdot 14, \theta=0 \cdot 00)$. These results, combined with the linkage data of a single large American family, suggest that the disease is caused by dominant mutations of the adult sodium channel, and that it is probably a genetically homogeneous disorder. Hyperkalaemic periodic paralysis is the first non-progressive myotonic disorder to be localised on the human genome.

The non-progressive myotonic disorders are a clinically and genetically heterogeneous group of muscle diseases having in common the variable symptom of myotonia (table 1 ). In vitro studies of the electrical membrane properties of muscle fibres in affected patients with these diseases have shown that the pathophysiological defects could be caused by disturbances in the voltage dependent gating of different ion channels. ${ }^{5}$

Periodic paralysis with hyperkalaemia during attacks was first conclusively described by Gamstorp ${ }^{3}$ in 1956 . She named the disorder adynamia episodica herditaria. Inheritance is autosomal dominant with high penetrance in both sexes. Three clinically different subtypes of hyperkalaemic periodic paralysis (PPII, MIM 170500) exist: (1) without myotonia, (2) with electromyographic and clinical myotonia, or (3) with paramyotonia. The prevalence of myotonic PPII is low and no reliable estimates exist for the Caucasian population.

Table 1 Non-progressive myotonic disorders.

\begin{tabular}{ll}
\hline Myotonia congenita $^{2}$ & MIM 160800 \\
Generalised myotonia $^{2}$ & MIM 255700 \\
Paramyotonia congenita $^{4}$ & MIM 168300 \\
Paralysis periodica paramyotonica $^{2}$ & \\
Hyperkalaemic periodic paralysis $^{3}$ & MIM 170500 \\
Normokalaemic periodic paralysis $^{11}$ & MIM 170600 \\
\hline
\end{tabular}


The clinical symptoms of PPII with myotonia start in the first or second decade of life and are characterised by episodic attacks of muscle weakness at rest after exercise. During the paralytic attack the serum potassium is variably raised. Attacks usually do not last longer than a few hours and can be precipitated by cold, hunger, rest after exercise, stress, potassium rich food, or potassium loading. After frequent and severe attacks patients may develop permanent proximal myopathy. Myotonic lid lag and percussion myotonia are usually present and may be aggravated at the beginning of the attack. The EMG recordings show myotonic discharges, which cannot be differentiated from other myotonic disorders, particularly paramyotonia congenita.

In vitro studies of muscle fibres in patients with myotonic PPII have shown that in the state of weakness the muscle fibres are depolarised to an extent that the membrane is inexcitable. A pathological inward sodium current, which can be completely blocked by tetrodotoxin, is the cause of the depolarisation. ${ }^{6}$ This sodium current was found to be conducted by non-inactivating sodium channels, which enter a pathological state of reduced single channel conductance. ${ }^{7}$

Recently the $\alpha$ subunit of the adult human skeletal muscle sodium channel, h-Na2, was cloned and localised to the long arm of chromosome $17 .^{8}$ In addition, this CDNA probe was shown to be linked with no recombinants to the human growth hormone gene, GH1, on 17q22-24. Analysis of linkage of an extended American family with myotonic PPII showed a combined lod score of $Z=7.02$ at $\theta=0.00$ with the cDNA probes $\mathrm{h}-\mathrm{Na} 2$ and $\mathrm{GH} 1 .^{8}$ From these results the authors drew the conclusion that the $\alpha$ subunit of the adult human skeletal muscle sodium channel might be the site of the primary defect in myotonic PPII. However, further linkage analyses in families from different ethnic backgrounds are required to exclude the possibility that mutations at different loci might produce the same clinical manifestation in different families.

\footnotetext{
Materials and methods

FAMILY STUDIES

After informed consent had been obtained, we studied five German and one British myotonic PPII family. The German family members were personally seen by three of the authors (MCK, KR, FL-H) and the diagnosis was confirmed by examining the patients and reviewing their records for personal history, serum potassium levels, and EMG results. The phenotype in the German families was consistent with myotonic PPII. Two of these patients have been reported previously. ${ }^{69}$ In addition, we studied one British family (seen by MCK and PSH) with the typical features of myotonic PPII; serum potassium
}

levels were in the normal range, but potassium loading was not performed. Altogether we studied 31 affected and 19 unaffected family members and nine spouses. The oldest patient was 81 years of age and the youngest 19 years.

\section{DNA ANALYSIS}

Genomic DNA was extracted from peripheral blood by the salting out procedure. ${ }^{10}$ Samples of DNA were digested to completion with the restriction enzymes BglII and HindII under conditions recommended by the manufacturer (table 2). Resulting DNA fragments were electrophoresed in $0.9 \%$ agarose gels, transferred to nylon membranes, and hybridised to the radiolabelled CDNA insert of $h$ $\mathrm{Na} 2$ and hGH. Linkage analysis was carried out with the LINKAGE package of computer programs (version 5.03 , updated by $\mathrm{J} \mathrm{Ott).}{ }^{12}$ For the analysis, autosomal dominant inheritance with $100 \%$ penetrance of the PPII gene was assumed. All unaffected subjects were beyond the age of risk.

\section{Results}

The lod scores at recombination fractions from 0.00 to $\mathbf{0 . 4}$ for PPII versus the h-Na2 and hGH polymorphisms (separately and their combined haplotypes) are shown in table 3 . There were 23 scorable meioses; the disease was transmitted 13 times through the female line and five times through the male line. All key family members were typed with the $\mathrm{h}-\mathrm{Na} 2$ and $\mathrm{hGH}$ gene probes. The informative polymorphism with either probe was used to type the remaining family members. There was no recombination between the markers and PPII; one family was only partly informative. The haplotype of the two probes is closely linked to PPII with a maximum lod score of 7.14 at $\theta=0.00$ (support interval 0.00 to 0.07 ). The support intervals for the $\mathrm{h}-\mathrm{Na} 2$ data and hGH data alone were 0.00 to 0.15 and 0.00 to 0.09 , respectively. The British family on its own showed a multipoint lod score of 2.76 at $\theta=0.00$ with no recombinants.

Table 2 RFLPs used in this study.

\begin{tabular}{llll}
\hline Locus & RFLP & $\begin{array}{c}\text { Allele } \\
\text { sizes }(k b)\end{array}$ & $\begin{array}{c}\text { Allele } \\
\text { frequencies }\end{array}$ \\
\hline h-Na2 & BglII & A1 25 & $0.25^{*}(0.27)^{8}$ \\
& & A2 15 & $0.75^{*}(0 \cdot 73)^{8}$ \\
hGH & HindII & A1 6.7 & $0.62^{*}(0.67)^{8}$ \\
& & A2 4.5 & $0.38^{*}(0.33)^{8}$ \\
\hline
\end{tabular}

* Data from this study. 
Table 3 Results (lod scores Z) of linkage analysis between chromosome 17 markers and hyperkalaemic periodic paralysis.

\begin{tabular}{|c|c|c|c|c|c|c|c|c|}
\hline \multirow[t]{2}{*}{ Linkage comparison } & \multicolumn{8}{|c|}{ Recombination fraction $\theta$} \\
\hline & 0.000 & 0.001 & 0.01 & 0.05 & $0 \cdot 10$ & 0.20 & $0 \cdot 30$ & 0.40 \\
\hline $\begin{array}{l}\text { PPII - h-Na2 } \\
\text { PPII - hGH } \\
\text { PPII - h-Na2/hGH }\end{array}$ & $\begin{array}{l}3 \cdot 06 \\
5 \cdot 02 \\
7 \cdot 14\end{array}$ & $\begin{array}{l}3.05 \\
5 \cdot 01 \\
7 \cdot 12\end{array}$ & $\begin{array}{l}2.99 \\
4.92 \\
6.99\end{array}$ & $\begin{array}{l}2 \cdot 73 \\
4.50 \\
6.39\end{array}$ & $\begin{array}{l}2.40 \\
3.94 \\
5.61\end{array}$ & $\begin{array}{l}1.72 \\
2.71 \\
3.97\end{array}$ & $\begin{array}{l}0.98 \\
1.44 \\
2 \cdot 24\end{array}$ & $\begin{array}{l}0.29 \\
0.33 \\
0.66\end{array}$ \\
\hline PPII - h-Na2/hGH & \multicolumn{8}{|c|}{ Data from Fontaine et $a l^{8}$} \\
\hline $\begin{array}{l}\text { Combined multipoint lod score from our } \\
\text { data and Fontaine et } a l^{8}\end{array}$ & $14 \cdot 16$ & $14 \cdot 14$ & 13.90 & $12 \cdot 81$ & $11 \cdot 40$ & $8 \cdot 40$ & $5 \cdot 16$ & 1.81 \\
\hline
\end{tabular}

\section{Discussion}

The candidate gene approach has been used by many investigators trying to map disorders on the human genome. So far it has been successful in connective tissue disorders, for example, osteogenesis imperfecta, ${ }^{13}$ and recently in localising malignant hyperthermia ${ }^{14}$ and central core disease. ${ }^{15}$

The first data for mapping myotonic PPII by the candidate gene approach were reported by Fontaine et al, ${ }^{8}$ who took advantage of the pathophysiological knowledge about the disorder and the availability of the rat sodium channel sequence to clone the human homologue and map the human gene to $17 \mathrm{q}$. The combined linkage data (table 3) of the six European families and the single American family make it very likely that the primary defect is indeed in the muscle sodium channel and that PPII with myotonia is probably genetically homogeneous. The linkage analyses show one of the rare successful candidate gene approaches.

With the localisation of myotonic PPII, the important question about heterogeneity of the autosomal dominant, non-progressive myotonic disorders with episodic paralysis might be answered, a subject of long standing discussion ${ }^{1617}$ for the following reasons. Myotonic PPII patients with hyperkalaemic periodic paralysis in combination with paramyotonia ${ }^{2}$ (paralysis periodica paramyotonica) suffer from hyperkalaemic attacks, but have in addition cold induced stiffness followed by flaccid weakness, which is a hallmark of paramyotonia congenita. ${ }^{4}$ In normokalaemic periodic paralysis attacks resemble PPII, but without significant increase of serum potassium during the attack. ${ }^{11}$

All these disorders are thought to be associated with altered functions of the muscle sodium channels. Only molecular studies in well defined families will provide further evidence of whether these disorders are variants of the same genetic condition or genetically different diseases. The slightly different clinical symptoms in myotonic disorders with episodic weakness might be the result of malfunctions in the same muscle sodium channel. Channel disturbances could be caused by an allelic series of mutations at the same gene locus, by post-transcriptional or post-translational modifications of the gene product.

We would like to thank P Seeburg for supplying the hGH probe. We are grateful to Dr K Bathke for helping in blood sampling and to Gisela Grahmann for excellent technical assistance. We especially want to thank all the families whose participation made this study possible. The work was supported by the Deutsche Forschungsgemeinschaft (DFG), the Deutsche Gesellschaft Bekämpfung der Muskelkrankheiten (DGBM), and the Muscular Dystrophy Association (MDA).

1 Pierson M, Leheup B, Jeandel C. Adynamie épisodique héréditaire: maladie de Gamstorp, paramyotonie d'Eulenburg? $\boldsymbol{f}$ Genet Hum 1989;37:379-87.

2 Becker PE. Myotonia congenita and syndromes associated with myotonia. In: Topics in human genetics. Stuttgart: Georg Thieme Verlag, 1977.

3 Gamstorp I. Adynamia episodica hereditaria. Acta Paediatr 1956;45(suppl 108):1-126.

4 Becker PE. Paramyotonia congenita (Eulenburg). In: Fortschritte der allgemeinen und klinischen Humangenetik. Stuttgart: Georg Thieme Verlag, 1970.

5 Rüdel R, Lehmann-Horn F. Membrane changes in cells from myotonia patients. Physiol Rev 1985;65:310-56.

6 Lehmann-Horn F, Küther G, Ricker K, Grafe P, Ballanyi K, Rüdel R. Adynamia episodica hereditaria with myotonia: a non-activating sodium current and the effect of extracellular pH. Muscle Nerve 1987;10:363-74.

7 Lehmann-Horn F, Iaizzo PA, Hatt H, Franke C. Altered gating and reduced conductance of single sodium channels in hyperkalemic periodic paralysis. Pflügers Archiv 1991;418:297-9.

8 Fontaine B, Khurana TS, Hoffman EP, et al. Hyperkalemic periodic paralysis and the adult muscle sodium channel $\alpha$ subunit gene. Science 1990;250:1000-2.

9 Lehmann-Horn F, Rüdel R, Ricker K, Lorkovic H, Dengler R, Hopf HC. Two cases of adynamia episodica hereditaria: in vitro investigation of muscle cell membrane and contraction parameters. Muscle Nerve 1983;6:113-21.

10 Miller SA, Dykes DD, Polesky HF. A simple salting out procedure for extracting DNA from human nucleated cells. Nucleic Acids Res 1988;16:1215.

11 Poskanzer DC, Kerr DNS. A third type of periodic paralysis, with normokalemia and favourable response to sodium chloride. Am 7 Med 1961;31:328-42.

12 Lathrop GM, Lalouel JM, Julier C, Ott J. Strategies for multilocus linkage analysis in humans. Proc Natl Acad Sci $U S A$ 1984;81:3443-6.

13 Byers P, Tsipouras P, Bonadio J, Starman B, Schwartz R. Perinatal lethal osteogenesis imperfecta (OI type II): a biochemically heterogeneous disorder usually due to new mutations in the genes for type I collagen. Am $\mathcal{f}$ Hum Genet 1988;42:237-48. 
14 MacLennan DH, Duff C, Zorzato F, et al. Ryanodine receptor gene is a candidate for predisposition to malignant hyperthermia. Nature 1990;343:559-61.

15 Haan EA, Freemantle CJ, McCure JA, Friend KL, Mulley JC. Assignment of the gene for central core disease to chromosome 19. Hum Genet 1991;86:187-90.

16 De Silva SM, Kuncl RW, Grifin JW, Cornblath DR, Chavous- tie S. Paramyotonia congenita or hyperkalemic periodic paralysis? Clinical and electrophysiological features of each entity in one family. Muscle Nerve 1990;13:21-6.

17 Serratrice G, Desnuelle C. Paramyotonie congénitale, adynamie épisodique héréditaire ou paralysie périodique familiale paramyotonique et hyperkaliémique. Semin Hop Paris 1982; 